\title{
MONITORING AND PREVENTION OF FOREST FIRES USING WIRELESS SENSOR NETWORKS
}

\author{
Vuk Gajić, \\ Gordana Dražić, \\ Nikola Dražić \\ Environment and Sustainable Development, \\ Singidunum University, \\ Belgrade, Serbia
}

\begin{abstract}
:
Forest fires as a specific type of natural hazard are steadily increasing in recent decades in the world and Serbia. The most significant negative consequences are environmental (devastation of forest ecosystems), economic (resources loss and financial damage), and social (environmental pollution, loss of human lives). Due to the numerous factors that allow the occurrence and spread of forest fires, it is necessary to use modern methods for their early detection. Many methods and safety systems have been developed to prevent and to monitor forest fires. In addition to expensive remote-sensing monitoring systems (expensive specially equipped aircraft and satellites), there are more practical solutions. Satellite system networks technology has its drawbacks, data collection is difficult or impossible due to bad weather (cloudiness, smoke). Wireless network sensors have their advantages: low cost, reliability and easy installation, wireless data transfer, and low power consumption. The system is applicable in various fields such as medicine, agriculture, security, forest fire-prevention, etc. Wireless network sensors system monitor forest fires even when they are forming, regardless of the accessibility of the terrain, the size of the space of interest, or its distance. The information collected allows for taking quick and effective action to suppress and extinguish forest fires.
\end{abstract}

Keywords:

orest fires, natural hazards, sensors, real-time assessment.

\section{INTRODUCTION}

Today, technologies are developing at a high speed, so that they have become available and popular for monitoring and prevention of natural hazards in the environment [1]. Creating and connecting to databases provides real-time data that is crucial. Data transfer is fast and high quality and is used for monitoring purposes, in smart buildings, agriculture, traffic, earthquake research, environmental protection, etc. Application in the field of environmental protection is of great importance due to the constant anthropogenic pressures that grow from year to year. The need to protect property, material goods, and nature has become a daily need of society. 


\section{FOREST FIRE}

One of the natural hazards that are especially dangerous for the environment are forest fires and if they are detected within 6 minutes of their outbreak, they are relatively easy to extinguish (NFDRS - National Fire Hazard Assessment System). Numerous techniques for early detection of forest fires have been developed.

The organizations, "The Center for Research on the Epidemiology of Disasters (CRED)" and "Munich Reinsurance Company (Munich RE)", based on cadastres of natural disasters and definitions, classified forest fires into a group of natural climate disasters [2], [3]. It is important to emphasize that this type of natural hazard is most common in the territory of the Republic of Serbia [4] (Table 1).

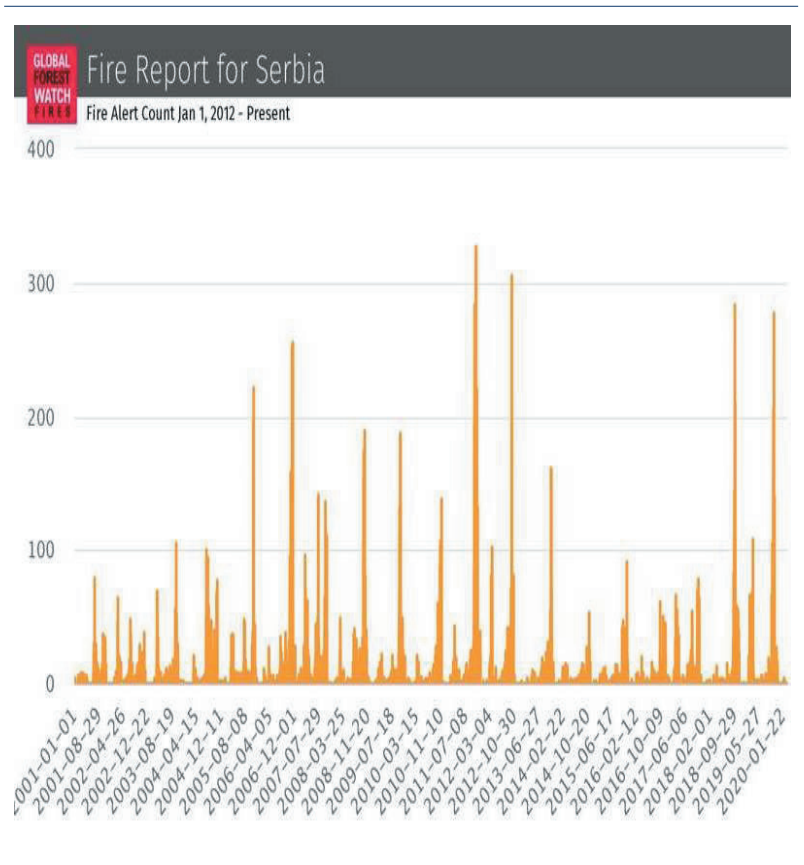

Table 1. STATISTICS ON FIRES IN THE REPUBLIC OF SERBIA FROM 2001 TO THE PRESENT

(GLOBAL FOREST WATCH FIRES)

Without forest ecosystems, there would be no life on the planet as we know it today. The role of forest systems in gas exchange is well known. During the process of photosynthesis, forests absorb carbon dioxide, produce oxygen, and release it into the atmosphere. Forests are also a natural filter of the atmosphere and slow down climate change. $30 \%$ of the earth's surface (4 billion hectares) is covered by forests, while in Europe the forest cover is about 34\% (193 million hectares, excluding Russia) [5]. As for the Republic of Serbia, it is considered a medium-forested country with $29.1 \%$ under forest cover (2.25 million hectares) according to data taken from the site Serbia Forests (www.srbijasume.rs). Serbia is therefore close to the global average of $30 \%$, but it is, therefore lower than the European average, ie. of $46 \%$ (Table 2).

\begin{tabular}{|c|c|c|c|c|}
\hline & & Period & 2014 & 2017 \\
\hline Indicator & Teritory - NSTJ & & & \\
\hline \multirow[t]{8}{*}{ Forested land- total [Hectare] } & REPUBLLC OF SERBIA & & 2168746 & 2237511 \\
\hline & SRBJIA-North & & 185436.65 & 193440.11 \\
\hline & Beogradski region & & 61625.27 & 61987.21 \\
\hline & Region Vojvodine & & 123811.38 & 131452.9 \\
\hline & SRBIJA-South & & 1983309.35 & 2044070.89 \\
\hline & Region Šumadije i Zapadne Srbije & & 963740.88 & 980213.35 \\
\hline & Region Južne i lstočne Srbije & & 1019568.47 & 1063857.54 \\
\hline & Region Kosovo i Metohija & & $\ldots$ & ... \\
\hline \multirow[t]{8}{*}{ State-owned forested land [Hectare] } & REPUBLLC OF SERBIA & & 953218 & 963458 \\
\hline & SRBJJA-North & & 133986.07 & 135746.06 \\
\hline & Beogradski region & & 15242.31 & 15455.26 \\
\hline & Region Vojvodine & & 118743.76 & 120290.8 \\
\hline & SRBIJA-South & & 819231.93 & 827711.94 \\
\hline & Region Šumadije i Zapadne Srbjie & & 400580.42 & 403731.19 \\
\hline & Region Južne i Istočne Srbije & & 418651.51 & 423980.75 \\
\hline & Region Kosovo i Metohija & & ... & ... \\
\hline \multirow[t]{8}{*}{ Privately-owned forested land [Hectare] } & REPUBLIC OFSERBIA & & 1215528 & 1274053 \\
\hline & SRBIIA-North & & 51450.58 & 57694.05 \\
\hline & Beogradski region & & 46382.96 & 46531.95 \\
\hline & Region Vojvodine & & 5067.62 & 11162.1 \\
\hline & SRBIJA-South & & 1164077.42 & 1216358.95 \\
\hline & Region Šumadije i Zapadne Srbjie & & 563160.46 & 576482.16 \\
\hline & Region Južne i Istočne Srbije & & 600916.96 & 639876.79 \\
\hline & Region Kosovo i Metohija & & ... & ... \\
\hline
\end{tabular}

Table 2. THE TERRITORY OF THE REPUBLIC OF SERBIA UNDER FOREST (REPUBLIC STATISTICAL OFFICE, REPUBLIC OF SERBIA).

Suorce: www.stat.gov.rs

With the increase of the human population and the need for resources, the anthropogenic impact also increases, which creates favorable conditions for the outbreak of forest fires and uncontrolled combustion of combustible material in rural areas.

Fires are caused by a combination of physicochemical processes. The so-called "fire triangle" is formed by a combination of combustible material, air, and heat sources. The following factors have a decisive influence on the formation and movement of fires: climate, flammable material, and topography (altitude, exposure, terrain slope, terrain configuration) [6].

Forest fires are an increasingly common occurrence across the planet and are mainly responsible for anthropogenic factors (95\%), although they can also occur naturally (5\%) [7], [8]. Wildfires are unpredictable and difficult to control because you are usually admitted late. Forest fires occasionally have a regulatory role and contribute to the establishment of ecological balance, 
but they also cause devastation within ecosystems. In addition to soil and water pollution, fires also lead to the loss of nutrients and microorganisms in the soil. When they expand, they are difficult to control. Environmental, economic, and cultural losses are difficult to compensate [9], [10].

Forest fires during the outbreak on the ground floor are mostly without a large flame, they create smoke and generate heat. For that reason, modern sensors are needed to detect this type of fire, which can detect even the smallest temperature oscillations and the presence of smoke. If ground forest fires are not detected in time, they spread and form crown fires with a strong flame. At high temperatures, the sensors are destroyed.

Forest fires are the most extreme type of forest devastation, and therefore a global problem that requires the involvement of all relevant institutions in the fight to prevent and combat them. Over 50,000 fires occur worldwide each year, leaving behind devastation. 40 million hectares of forests are destroyed in fires, leading to a reduction in the population of wildlife and large casualties [11].

Monitoring sites of interest is often not practical and possible due to the configuration of the terrain and large expanses. Therefore, the need for monitoring using modern technologies is necessary for taking measures to warn and prevent damage from forest fires. With the help of these technologies, information is quickly transmitted in real-time from inaccessible locations. By monitoring sudden temperature rises, steps can be taken effectively to prevent the spread of forest fires. The collected data can be displayed using a GIS program in the form of maps [12].

\section{FIRE MONITORING TECHNOLOGIES}

An overview of available technologies singled out five, with the best parameters: Wireless Network Sensors, Image and Image Processing, Satellites, Unnamed Flying Objects / Aircraft, and Radio Acoustics.

The parameters used when comparing technologies are as follows: cost, real-time convenience, mobility, energy consumption, fire spread prediction, terrain coverage, data transmission delay detection, false alarms, fire location error (Table 3).

\begin{tabular}{|c|c|c|c|c|c|}
\hline Comparison & \begin{tabular}{|l|}
$\begin{array}{l}\text { Wireless } \\
\text { sensor } \\
\text { Networks }\end{array}$ \\
\end{tabular} & \begin{tabular}{|l|} 
Image and \\
Video \\
Processing \\
\end{tabular} & Satellite & $\begin{array}{l}\text { UAV/ } \\
\text { Airborne }\end{array}$ & $\begin{array}{l}\text { Radio- } \\
\text { acoustic }\end{array}$ \\
\hline Cost & Low & High & Very High & High & Medium \\
\hline Practicality & High & Medium & Very High & High & Very Low \\
\hline \begin{tabular}{|l|}
$\begin{array}{l}\text { Detection } \\
\text { device } \\
\text { mobility }\end{array}$ \\
\end{tabular} & Fixed & Fixed & Mobile & Mobile & Fixed \\
\hline \begin{tabular}{|l|} 
Battery \\
power \\
provided \\
through \\
\end{tabular} & $\begin{array}{l}\text { Rechargeable } \\
\text { Devices }\end{array}$ & $\begin{array}{l}\text { Rechargeable } \\
\text { Devices }\end{array}$ & Solar & $\begin{array}{l}\text { Rechargeable } \\
\text { Devices }\end{array}$ & $\begin{array}{l}\text { Rechargeable } \\
\text { Devices }\end{array}$ \\
\hline $\begin{array}{l}\text { Information } \\
\text { about fire } \\
\text { behavior }\end{array}$ & Yes & No & Yes & Yes & No \\
\hline $\begin{array}{ll}\text { Region } & \text { of } \\
\text { Intrest }\end{array}$ & $\begin{array}{|ll|}\text { Cant } & \text { be } \\
\text { extended } & \\
\end{array}$ & Limited & $\begin{array}{l}\text { Complete } \\
\text { Forest }\end{array}$ & $\begin{array}{ll}\text { Can } & \text { be } \\
\text { extended } & \end{array}$ & Limited \\
\hline $\begin{array}{l}\text { Detection- } \\
\text { notification } \\
\text { delay } \\
\end{array}$ & Small & Long & Very Long & Long & Small \\
\hline False Alarm & Low & Medium & Very Low & Medium & High \\
\hline $\begin{array}{l}\text { Fire } \\
\text { localization } \\
\text { error }\end{array}$ & Low & High & Very High & High & High \\
\hline
\end{tabular}

Table 3. COMPARISON OF DIFFERENT

TECHNOLOGIES FOR FOREST FIRE DETECTION BY PARAMETERS

- According to the parameter "Costs", this technology can be divided into three groups:

Taking into account the parameters of the mentioned technologies for installation and operating costs, we divided the technologies into three groups: cheap, medium, and expensive.

1) Cheap (Wireless Network Sensors)

2) Medium (Radio Acoustics)

3) Expensive (Image and video processing, Unnamed flying objects/aircraft, Satellites)

- According to the parameter "Practicality", this technology can be divided into three groups:

Taking into account the parameters of the mentioned technologies we divided the technology (according to the possibilities of their practical installation and use) into three groups: impractical, medium practical, and practical.

1) Impractical (Radio Acoustics)

2) Medium practical (Image and video processing)

3) Practical (Satellites, Wireless Network Sensors, Unnamed Flying Objects / Aircraft)

- According to the parameter "Mobility", this technology can be divided into 2 groups:

Taking into account the mobility parameters of the mentioned technologies, we divided the technologies into two groups: stationary and mobile.

1) Stationary (Wireless network systems, Image and video processing, Radio acoustics) 
2) Mobile (Satellites, Unnamed Flying Objects/Aircraft)

- According to the parameter "Energy consumption", this technology can be divided into 2 groups:

Taking into account the parameters for the energy consumption of the mentioned technologies, we divided the technologies into two groups: rechargeable devices and solar devices.

1) Rechargeable devices (Wireless network systems, Image and video processing, Unnamed flying objects/aircraft, Radio acoustics)

2) Solar devices (Satellites)

- According to the parameter "Fire spread prediction", these technologies can be divided into 2 groups:

Taking into account the parameters of technologies for the prediction of the behavior of forest fires, we divided the technologies into two groups: anticipate the spread of fire and do not predict the spread of fire.

1) Anticipate the spread of fire (Wireless network systems, Satellites, Unnamed flying objects/aircraft)

2) Do not predict the spread of fire (Image and video processing, Radio acoustics)

- According to the parameter "Ability to cover the terrain", these technologies can be divided into 4 groups:

Taking into account the parameter for the ability of the technology to cover the terrain, we divided the technology into four groups: cannot be spread, limited, expandable, and all-terrain.

1) Cannot be spread (Wireless network systems)

2) Limited (Image and video processing, Radio acoustics)

3) Expandable (Unnamed Flying Objects / Aircraft, Radio Acoustics)

4) All-terrain (Satellites)

- According to the parameter "Detection-data transfer", this technology can be divided into 2 groups:

Taking into account the parameter for the ability of the technology for detection-data transfer, we divided the technology into two groups: a short time and a long time.

1) A short time (Wireless network systems, Radio acoustics)

2) A long time (Satellites, Unnamed flying objects/ aircraft, Image, and video processing)

- According to the parameter "False alarms", this technology can be divided into 3 groups:
Taking into account the parameter for the ability of technologies to detect false alarms, we divided the technology into three groups: low, medium, and high level.

1) Low (Satellites, Wireless Network Systems)

2) Intermediate (Unnamed flying objects/aircraft, Image and video processing)

3) High level (Radio acoustics)

- According to the parameter "Fire location error", these technologies can be divided into 2 groups:

Taking into account the parameter for the ability of technologies to detect fire locations, we divided the technology into two groups: low and high.

1) Low (Wireless Network Systems)

2) High (Image and video processing, Satellites, Unnamed flying objects/aircraft, Radio acoustics)

\section{WIRELESS NETWORK SYSTEMS}

Based on the review of all parameters, the technology of Wireless Network Systems is derived from the others.

Wireless network sensors were developed as one of the key technologies in the twenty-first century for monitoring and tracking, data collection, and processing. Systems that use orthophotos (satellites) in detecting forest fires have their drawbacks such as weather conditions (cloud cover) and installation and technical costs. The sensor network consists of devices distributed in the field with various sensor accessories that accurately monitor the state of the environment. Data transmission is wireless, and the technology is reliable, requires low energy consumption, and is financially available to the general public [13]. It is used in hard-to-reach locations. Due to their characteristics, these systems are used in various fields - from security, medicine, agriculture, to the monitoring of the already mentioned forest fires.

The installation of the sensor is simple and there is no need for frequent human interventions. The technology is affordable. By connecting a large number of sensors, a stationary network is formed. Each sensor within the network has its identification number and is capable of wireless communication, but also of collecting, processing, and forwarding information. False alarms rarely occur due to sensor failure. Thanks to the network arrangement of sensors, we can quickly and efficiently determine wind speed, air pressure, humidity, smoke, $\mathrm{CO}_{2}$, direction, and direction of forest fire [14]. 
Depending on the need, there are two types of wireless sensor networks: a system for occasional data collection (air temperature) and a system for detecting hazards (forest fire). Timely detection of forest fires is crucial to reduce damage.

The location is chosen based on the natural resource we want to protect and the potential risk of forest fires. Fires can be classified by size, frequency, shape, speed, intensity, etc. [15]. All the mentioned parameters become irrelevant if the fire is identified at the very beginning. Therefore, it is important to place the sensors at the optimal distance (about 400 sensors per square kilometer). Wireless sensors are placed along with the site at a distance of 50-150 m [16]. Each sensor within the network measures the set parameters (attributes). The sensors detect physical or chemical readings and convert them into a signal that they send to the control panel. After installation, the sensors are adjusted to the desired parameters for monitoring temperature, humidity, and wind speed. The temperature change is monitored in four ranges $\left(20-30^{\circ} \mathrm{C}\right.$ green risk zone, $30-40^{\circ} \mathrm{C}$ yellow risk zone, $40-50{ }^{\circ} \mathrm{C}$ orange risk zone, and $50-60{ }^{\circ} \mathrm{C}$ red risk zone) [17]. After calibration of the wireless sensor networks, the system connects to the database (application) with the help of which information is collected and stored. After receiving information based on real-time data processing and attributes, the competent person (Employee in charge of monitoring the database) monitors all the characteristics of the forest fire and based on them contacts the competent services (National services in charge of emergency interventions due to natural hazards). After fulfilling all the above conditions, the system is put into operation.

To establish successful monitoring of natural hazards, ie protection against forest fires, it is necessary to fulfill the following steps:

- Site selection and sensor installation

- Sensor calibration according to desired parameters

- Connecting to a database (application)

- Real-time data processing

- Direct connection with the headquarters of the competent services

- Commissioning of the system

\section{CONCLUSION}

The paper deals with available technologies for monitoring and prevention of forest fires. By comparing the pros and cons of the available parameters, we have singled out the technology of Wireless Network Systems. Wireless network systems allow us to monitor forest fires in real-time with the help of remote detection, regardless of the accessibility of the terrain and the size of the area of interest and its distance. Installation and commissioning of the system are extremely affordable. By monitoring the protocols, important information can be efficiently submitted to the competent services, which can act on time in crises. Natural wealth and human lives are protected in a technologically innovative way with reduced real-time risk.

\section{REFERENCES}

[1] J. Zhang, W. Li, N. Han, J. Kan: Forest Fire Detection System Based on a Zigbee Wireless Sensor Network, Front. For. China, Springer Verlag, pp.369-374, 2008.

[2] VIIRS 375m NRT - NRT VIIRS 375 m Active Fire Alert product VNP14IMGT. Available on-line [https:/earthdata.nasa.gov/firms]. DOI: 5067/FIRMS/ VIIRS/VNP14IMGT.NRT.001.

[3] MODIS Collection 6 NRT - MODIS Collection 6NRT Hotspot/Active Fire Alert Detections MCD14DL. Available on-line [https://earthdata.nasa.gov/firms]. DOI:5067/FIRMS/MODIS/MCD14DL.NRT.006

[4] Lukić, T., Gavrilov, B. M., Marković, B. S., Komac, B., Zorn, M., Mlađan, D., Đorđević, J., Milanović, M., Vasiljević, A. Đ., Vujičić, D. M., Kuzmanović, B., Prentović, R. (2013): Classification of natural disasters between the legislation and application: the experience of the Republic of Serbia. Acta geographica Slovenica, 53-1, pp. 149-164.

[5] Aleksić, P., Krstić, M., Jančić, G. (2009): Forest fires - an ecological and economic problem in Serbia. Botanica Serbica, 33 (2), pp. 169-176.

[6] Aleksić, P., Jančić, G. (2011): Zaštita šuma od šumskih požara u Javnom preduzeću „Srbijašume”. Šumarstvo, broj 1-2, strana 95-110.

[7] E. Zervas, O. Sakkas, S. Hadjieftymiades, C. Anagnostopoulos, Fire detection in the urban-rural interface through fusion techniques, in Mobile Adhoc and Sensor Systems, 2007. MASS 2007. IEEE International Conference on, 2007, pp. 1-6.

[8] Radovanović, M., Pereira Gomes, J.F., (2008): Sunčeva aktivnost i šumski požari. Geografski institut „Jovan Cvijič" SANU, knjiga 71, Beograd. 
[9] Kre, P. Ymir, I, B. Hrvoje, V. Marin, Early forest fire detection with sensor networks: Sliding window skylines approach, 1430151 725-732 (2008).

[10] M. Hefeeda, M. Bagheri, Wireless sensor networks for early detection of forest fires, in Mobile Adhoc and Sensor Systems, 2007. MASS 2007. IEEE International Conference on, 2007, pp. 1-6.

[11] Lukić, T., Marić, P., Hrnjak, I., Gavrilov, M.B., Mlađan, D., Zorn, M., Komac, B., Milošević, Z., Marković, S.B., Sakulski, D., Jordaan, A., Đorđević, J., Pavić, D., Stojsavljević, R. 10 Researches Review DGTH | 45-1, 1-10, 2016 (2017): Forest fire analysis and classification based on a Serbian case study. Acta geographica Slovenica, 57-1, pp. 1-13.
[12] [12] B. S. Lee, M. E. Alexander, B. C. Hawkes, T. J. Lynham, B. J. Stocks, P. Englefield, Information systems in support of wildland fire management decision making in Canada, Computers and Electronics in Agriculture 37 (1-3) (2002) 185-198, DOI: 10.1016/S0168-1699(02)00120-5.

[13] I. Kurtis Kredo, M. Prasant, Medium access control in wireless sensor networks, Comput. Netw. 51 (4) (2007) 961-994, 1223795.

[14] J. Lloret, M. Garcia, D. Bri, S. Sendra, A wireless sensor network deployment for rural and forest fire detection and verification, Sensors 9 (11) (2009) 8722-8747. 